\title{
Fabrication and Condensate Microdrop Self-Propelling of Biomimetic Nanostructured Polymer Surfaces without Chemical Modification
}

Han-Xiong Huang* and Yue An

Lab for Micro Molding and Polymer Rheology, Guangdong Provincial Key Laboratory of Technique and Equipment for Macromolecular Advanced Manufacturing, South China University of Technology, Guangzhou 510640, P. R. China

*Corresponding authors: E-mail address: mmhuang@scut.edu.cn (H.-X. Huang).

\section{Supporting Information}

\section{S1. Fabrication of Biomimetic Polypropylene Replica}

The overall process for fabricating the biomimetic polypropylene (PP) replica includes the nickel replica fabrication and PP replica molding.

The forewings of cicada Cryptotympana atrata Fabricius living in Beijing were taken as original wings. To remove contaminants on their surfaces, the original wings were rinsed with deionized water cautiously before used as original templates. The cleaned wings were treated by sensitization and activation, in which the compositions and concentrations are listed in Table S1. Specifically, the wings were first immersed in the sensitization solution and then in the activation solution, both for $3 \mathrm{~min}$ at $25^{\circ} \mathrm{C}$. In the sensitization process, sodium dodecyl sulfonate $\left(\mathrm{C}_{12} \mathrm{H}_{25} \mathrm{SO}_{4} \mathrm{Na}\right)$ was used as a surfactant to improve hydrophilicity of the wing surfaces. So the sensitization and activation solutions could fully penetrate into the gaps between the nanopillars on the wings, thus ensuring the nanopillars to be entirely covered by palladium chloride $\left(\mathrm{PdCl}_{2} \cdot \mathrm{H}_{2} \mathrm{O}\right)$ in the activation solution. Then the wings were dried in ambient atmosphere. The 
covered palladium catalytic nuclei on the wings can be used as release of metal ions in the reduction reaction of subsequent electroless plating.

Table S1. Compositions and Concentrations in Sensitization and Activation Solutions for Wing Treatment

\begin{tabular}{lll}
\hline Step & Composition & Concentration \\
\hline Sensitization & $\mathrm{SnCl}_{2} \cdot \mathrm{H}_{2} \mathrm{O}$ & $10 \mathrm{~g} / \mathrm{L}$ \\
& $\mathrm{HCl}$ & $40 \mathrm{~mL} / \mathrm{L}$ \\
& $\mathrm{C}_{2} \mathrm{H}_{25} \mathrm{SO}_{4} \mathrm{Na}$ & $0.5 \mathrm{~g} / \mathrm{L}$ \\
Activation & $\mathrm{PdCl}_{2} \cdot \mathrm{H}_{2} \mathrm{O}$ & $1 \mathrm{~g} / \mathrm{L}$ \\
& $\mathrm{HCl}$ & $10 \mathrm{~mL} / \mathrm{L}$ \\
\hline
\end{tabular}

The nickel replica was fabricated via combining the electroless plating with electroplating. The compositions and concentrations of the solutions in the corresponding stages are listed in Table $\mathrm{S} 2$. The aforementioned treated wing was fixed on a supporting glass-slide and then immersed into the electroless nickel plating solution with magnetic stirring at $50^{\circ} \mathrm{C}$. The solution was adjusted to a $\mathrm{pH}$ value of 8 using ammonia water. Nickel sulfate $\left(\mathrm{NiSO}_{4} \cdot 6 \mathrm{H}_{2} \mathrm{O}\right)$ and sodium hypophosphite $\left(\mathrm{NaH}_{2} \mathrm{PO}_{2} \cdot \mathrm{H}_{2} \mathrm{O}\right)$ were used as main salt and reductant, respectively, in the electroless plating solution. After electroless plating for $1 \mathrm{~h}$, the wing covered with a conductive nickel layer was taken out from the solution and then washed thoroughly with deionized water to remove residual solution. The electroplating was subsequently performed with the conductive nickel covered wing as a cathode and a Ni-S plate as an anode at $50^{\circ} \mathrm{C}$. A power supply (IT7000 DC Power Supply, ITECH Electronic Co. Ltd, USA) was used to provide a constant current density of $4 \mathrm{~A} / \mathrm{dm}^{2}$ for the whole electroplating process. To guarantee the uniformity of the electrolyte solution, a magnetic stirring at $150 \mathrm{rpm}$ was applied. After electroplating for $2 \mathrm{~h}$, a nickel layer with a $\sim 00$ $\mu \mathrm{m}$ thickness was deposited on the conductive nickel layer of the wing. After removal of the wing, rinsing thoroughly and drying in air, a nickel replica was fabricated. 
Table S2. Compositions and Concentrations in Electroless Plating and Electroplating Solutions for Nickel Replica Fabrication

\begin{tabular}{lll}
\hline Step & Composition & Concentration \\
\hline Electroless plating & $\mathrm{NiSO}_{4} \cdot 6 \mathrm{H}_{2} \mathrm{O}$ & $30 \mathrm{~g} / \mathrm{L}$ \\
& $\mathrm{NaH}_{2} \mathrm{PO}_{2} \cdot \mathrm{H}_{2} \mathrm{O}$ & $30 \mathrm{~g} / \mathrm{L}$ \\
& $\mathrm{Na}_{3} \mathrm{C}_{6} \mathrm{H}_{5} \mathrm{O}_{7} \cdot 2 \mathrm{H}_{2} \mathrm{O}$ & $20 \mathrm{~g} / \mathrm{L}$ \\
Electroplating & $\mathrm{Ni}\left(\mathrm{SO}_{3} \mathrm{NH}_{2}\right)_{2} \cdot 4 \mathrm{H}_{2} \mathrm{O}$ & $300 \mathrm{~g} / \mathrm{L}$ \\
& $\mathrm{NiCl}_{2} \cdot 6 \mathrm{H}_{2} \mathrm{O}$ & $15 \mathrm{~g} / \mathrm{L}$ \\
& $\mathrm{H}_{3} \mathrm{BO}_{3}$ & $35 \mathrm{~g} / \mathrm{L}$ \\
\hline
\end{tabular}

The PP replicas were molded via the $\mu$-ICM technique. PP (grade CJS700, China Petrochemical Co.) was used as the material for molding the replica. The equipment used for fabricating the replicas comprises an $80 \mathrm{t}$ injection-molding machine (KM80SP180CX, KraussMaffei, Germany) and a microinjection compression mold equipped with a temperature control apparatus. The molding parameters, including injection rate $\left(154 \mathrm{~cm}^{3} / \mathrm{s}\right)$, melt temperature $\left(230{ }^{\circ} \mathrm{C}\right)$, mold temperature $\left(150{ }^{\circ} \mathrm{C}\right)$, compression force $(280 \mathrm{kN})$, and cooling time $(15 \mathrm{~s})$, were kept constant. It should be noted that the cycle time for molding the replicas was about $50 \mathrm{~s}$.

\section{S2. Condensation Tests on Cicada Wing and PP Replica Surfaces}

A simple refrigeration apparatus made from Peltier element was used to cool the samples and form condensate microdrops on their surfaces. Figure $2 \mathrm{a}$ was taken from the video captured using a high-speed camera (Fastec TS5, USA) with a zoom macro lens (ZOOM 7000, NAVITAR, USA), as shown in Figure S1a. For Figure $2 \mathrm{~b}$ and Figure 3, the testing apparatus was installed under an upright optical microscopy (Leica M125, Germany), and the condensation processes on the sample surfaces were captured by the high-speed camera coupled to the optical microscopy (Figure S1b). For Figure 1f and the insert shown in Figure 2a, the capture system was set up as Figure S1c. The temperatures on the sample surfaces were measured using a thermo tracer (TH5104R, NEC, Japan). The ambient temperature and relative humidity were measured using a hygrothermograph (HTC1, Yipinboyang, China). 

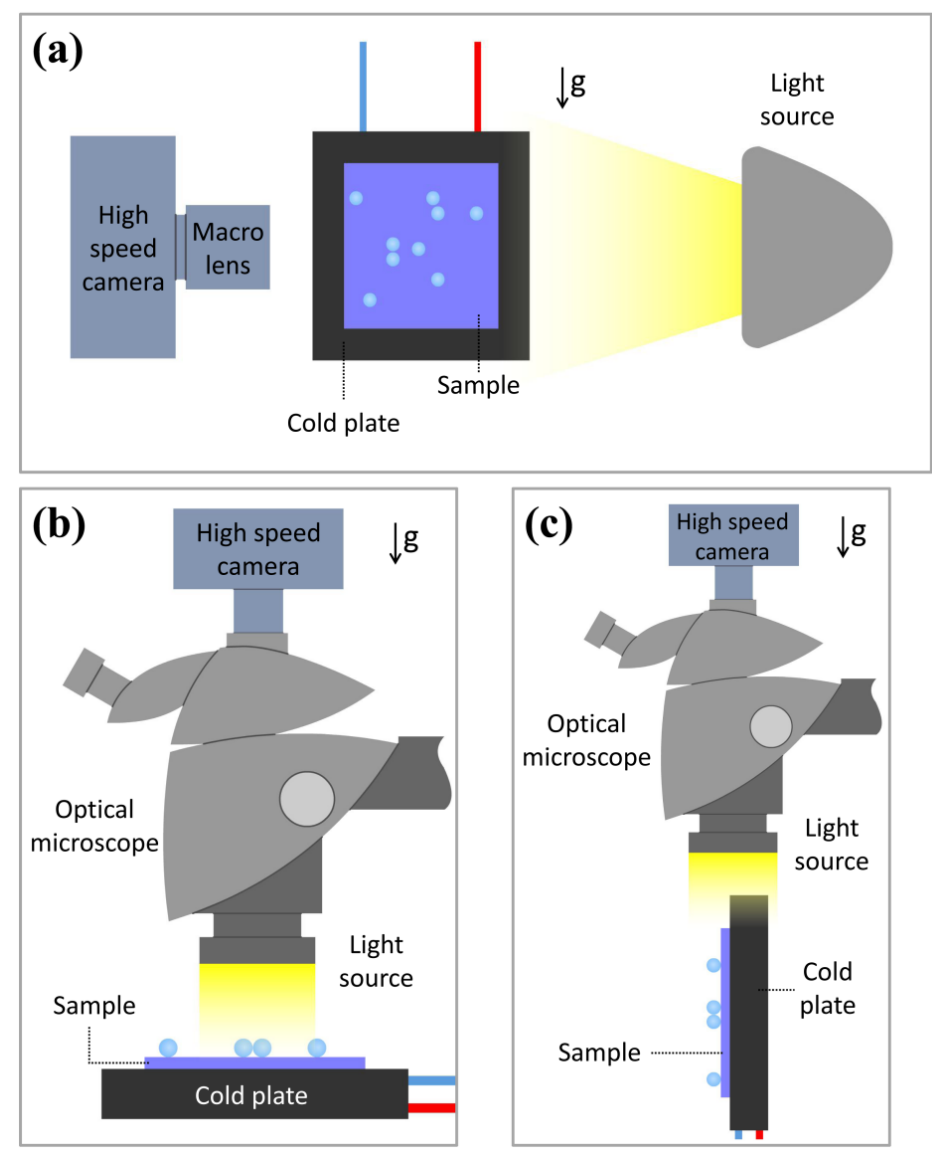

Figure S1. Schematics of Experimental Setup for Condensation Tests.

\section{S3. Energy Dispersive Spectroscopy (EDS) Spectrum of Nickel Replica}

The EDS spectrum of the nickel replica shown in Figure S2 indicates that its main component is nickel and it also contains small amounts of phosphorus.

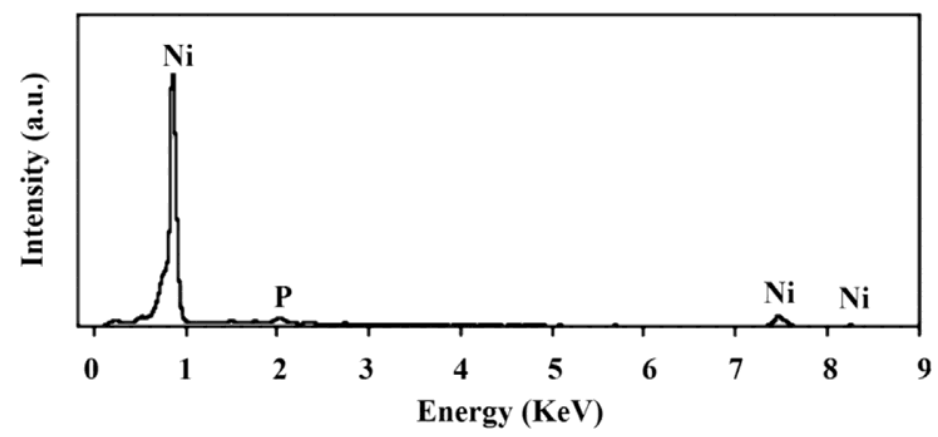

Figure S2. Energy Dispersive Spectroscopy Spectrum of Nickel Replica. 


\section{S4. Advancing Contact Angle on PP Counterpart Surface and Roughness Factor on PP Replica Surface}

The advancing contact angle $\left(\theta_{\mathrm{a}}\right)$ of $\sim 2 \mu \mathrm{L}$ droplets on the PP counterpart surface was measured using an automatic CA testing apparatus (OCA 40, Data Physics Corporation, Germany). The measurements were conducted at three different locations on the PP counterpart surface to obtain the average value. As shown in Figure S3, the $\theta_{\mathrm{a}}$ on the PP counterpart surface is $107.3 \pm 0.9^{\circ}$.

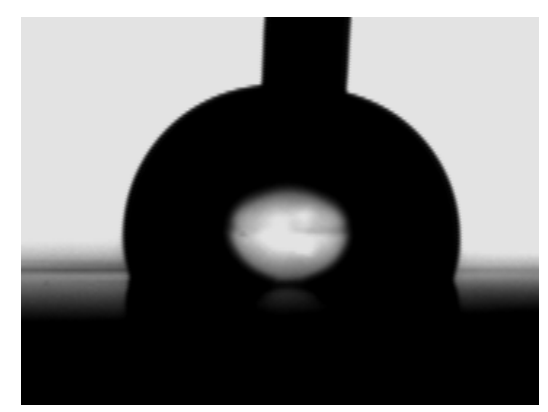

Figure S3. Advancing Contact Angle on PP Counterpart Surface.

The nanopillars are closely aligned on the PP replica with a mean tip diameter of $\sim 68 \mathrm{~nm}$, a mean base diameter of $\sim 147 \mathrm{~nm}$, a mean pitch of $\sim 179 \mathrm{~nm}$, and a mean height of $\sim 358 \mathrm{~nm}$. According to the geometric parameters of the nanopillars, a geometric model (shown in Figure $\mathrm{S} 4 \mathrm{a})$ is developed to calculate the roughness factor $(r)$ on the PP replica surface. The geometric model is divided into many pieces of elemental areas, as shown in Figure S4b. The real surface area $\left(A_{\mathrm{r}}\right)$ and geometric surface area $\left(A_{\mathrm{g}}\right)$ of an individual elemental area were measured to be $62993 \mathrm{~nm}^{2}$ and $13874 \mathrm{~nm}^{2}$, respectively (Figure S4c). Thus, the $r\left(=A_{\mathrm{r}} / A_{\mathrm{g}}\right)$ on the PP replica was calculated to be 4.54 . 
(a)

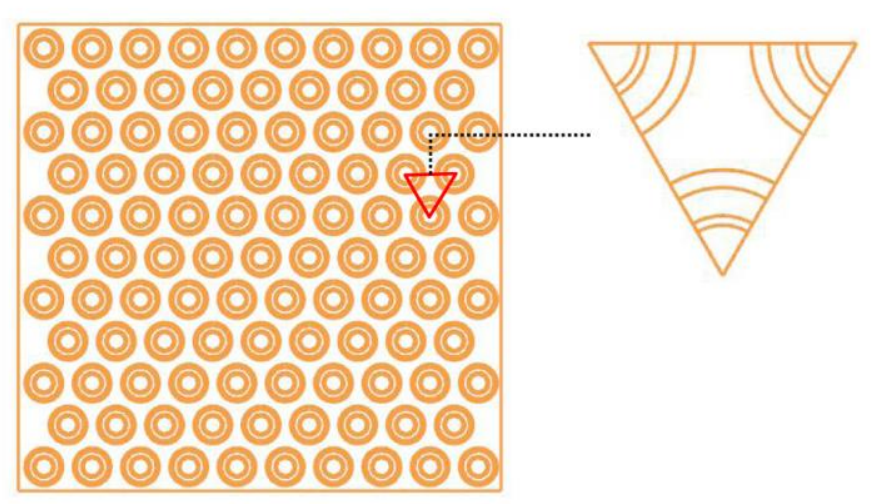

(c)

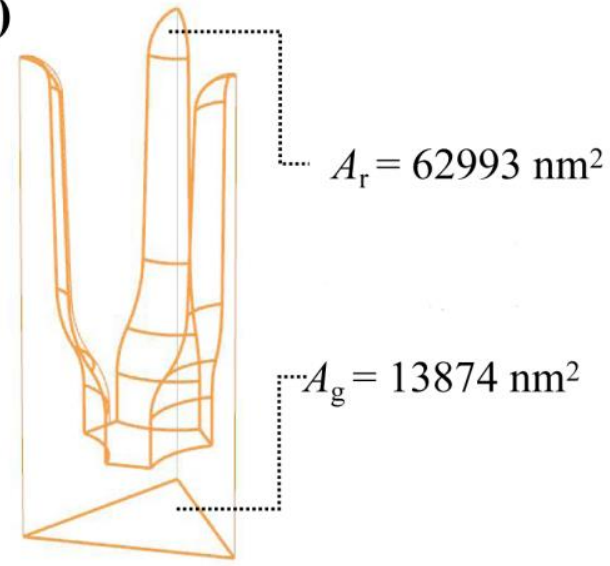

Figure S4. (a) Top-View of Geometric Model on PP Replica Surface, (b) Top-View of Individual Elemental Area of Geometric Model, and (C) Side-View of 3D Model for Individual Elemental Area. 